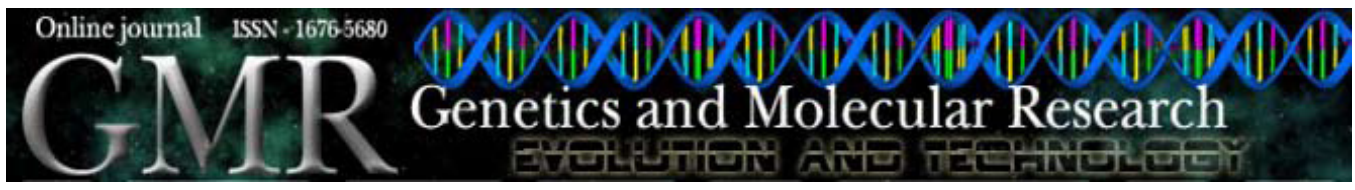

\title{
Genetic diversity in somatic mutants of grape (Vitis vinifera) cultivar Italia based on random amplified polymorphic DNA
}

\author{
S.H.Z. Maia, C.A. Mangolin, S.A.O. Collet and M.F.P.S. Machado \\ Departamento de Biologia Celular e Genética, \\ Universidade Estadual de Maringá, Maringá, PR, Brasil \\ Corresponding author: M.F.P.S. Machado \\ E-mail: mfpsmachado@uem.br
}

Genet. Mol. Res. 8 (1): 28-38 (2009)

Received October 7, 2008

Accepted October 22, 2008

Published January13, 2009

\begin{abstract}
Random amplified polymorphic DNA (RAPD) markers were used to detect polymorphism and to examine relationships among four table grape clones from northwestern Paraná, in southern Brazil. The 10 primers used for RAPD fingerprints generated 126 reproducible fragments, of which $63,68,76$, and 72 were polymorphic in cultivars Italia, Rubi, Benitaka, and Brasil, respectively. Among the primers, OPP-08 generated the highest number of fragments, whereas OPE-15 was the most efficient for discriminating polymorphic fragments. The distribution of the clones by cluster analysis indicated that there were no differences in RAPD markers between the colored mutant and the original clone (cultivar Italia), supporting the hypothesis that the non-colored and the colored mutant are the same cultivar. However, we found high levels of polymorphism within and between the cultivars Italia, Rubi, Benitaka,
\end{abstract}


and Brasil (65.1\%), contrary to a previous hypothesis that the four clones are genetically uniform. This confirmed our expectation of genetic variation among the clones and within each clone. We conclude that the primers are useful for analyzing the development of the genetic diversity within each of these clones.

Key words: Table grapes; Random amplified polymorphic DNA markers; Polymorphism; Vitis vinifera

\section{INTRODUCTION}

The table grape cultivar Italia (Piróvano 65) was introduced in the State of São Paulo, Brazil, in 1920 and its culture started in the north of Paraná in 1962 (Camargo, 1994). In 1972, a somatic mutation occurring in one side branch of Italia, grown in the Santa Mariana region, northeast Paraná, was the origin of cultivar Rubi (Kishino and Mashima, 1980). Another somatic mutation occurred in 1988 in one side branch of Italia, grown in the Floraí region, northwest Paraná, which gave rise to cultivar Benitaka (Sousa, 1996). Further, in 1991, one side branch of cultivar Benitaka, propagated in the Floraí area, was responsible for the start of Brasil cultivars. Cultivars Rubi, Benitaka, and Brasil have identical morphological, agronomic and partly biochemical features (muscat flavor, sugar content) to those of cultivar Italia. The 4 cultivars can only be distinguished by different pigmentation of their berries: green berries for cultivar Italia, light rosy-red colored berries for cultivar Rubi, more intense and uniform rosy-red colored berries for cultivar Benitaka, and black berries for cultivar Brasil. No other morphological or agronomic traits can be used to distinguish the four cultivars.

The economically important cultivars Italia, Rubi, Benitaka, and Brasil are traditionally grown in the rural region of Marialva, a town in the northwestern region of Paraná, southern Brazil. Their genetic relationship is of paramount importance for germplasm conservation, evolutionary aspects and future breeding programs. Isozymes were used to measure the genetic variability of the four table grape cultivars of Vitis vinifera, but were unable to detect allelic differences among clones (Oliveira-Collet et al., 2005). The lack of isozyme polymorphisms in a $V$. vinifera cultivar would indicate apparent genetic stability over the long period of cultivation of this cultivar. However, phenotypic reversion occurring either on a side branch or on the same bunch of the cluster of Benitaka cultivar $(0.4 \%)$ and Rubi cultivar $(0.27 \%)$, which exhibited the Italia cultivars' green color of the berry skin, and Brasil cultivar (28.57\%), which exhibited the Benitaka cultivars' rosy-red color of the berry skin reported by Oliveira-Collet et al. (2005), indicates genetic instability and a berry skin color polymorphism in grape cultivars of $V$. vinifera growing in the Marialva region. High frequency of the null EsT-3 carboxylesterase phenotype $(61.7 \%)$ also suggests the occurrence of genetic variations within cultivars (Orasmo et al., 2007).

In general, polymorphism of clonal material is rare and difficult to detect. In the current study, random amplified polymorphic DNA (RAPD) markers were used to detect polymorphism and to examine relationships among clone-propagated cultivars Italia, Rubi, Benitaka, and Brasil. RAPD marker analyses have been used to detect variations at the DNA level of grapevine clones (Regner et al., 2000). Closely related varieties were 
also differentiated by RAPD analysis (Zoghlami et al., 2001); these authors have also detected polymorphism at the intravariety level (Ulanovsky et al., 2002). The identification of clonal diversity in the $V$. vinifera cultivars is important to sustain genetic diversity in intensively cultivated crops since multiple clones of cultivars meet viticulturists' interests and offer several opportunities for grape breeding.

\section{MATERIAL AND METHODS}

Young leaves of seven healthy plants of Italia, Rubi, Benitaka, and Brasil cultivars of $V$. vinifera were collected from two vineyards in the northwestern region of the State of Paraná, Brazil. These vineyards are under the supervision of one agronomic engineer (Collet M) who has recorded the agronomic and developmental characteristics of the grape cultivars in field since the 1990s. Partially expanded leaves free of contaminants were colleted from vineyards in the regions of Marialva and Paiçandu (distance of approximately $20 \mathrm{~km}$ ) during the growing season, in August-October 2003 (Table 1). Cultivar Italia vineyards cultured in Marialva were established in 1971 (28 years old) whereas cultivars Benitaka, Rubi, and Brasil were established in 1997 (7 years old). In Paiçandu, the cultivar Italia, Rubi, Benitaka, and Brasil vineyards were also established in 1997 (Collet M, personal information). Samples were stored individually in labeled plastic mesh bags to avoid the mixing of cultivars, maintained in ice $\left(4^{\circ} \mathrm{C}\right)$, and transferred to the laboratory. Samples were frozen in liquid nitrogen at the laboratory and kept at $-80^{\circ} \mathrm{C}$ until DNA extraction.

DNA was extracted according to protocols originally described by Lodhi et al. (1994) and Thomas et al. (1993), with minor modifications. Modifications consisted of the utilization of $100 \mathrm{mg}$ leaves from individual vines in both protocols instead of 0.5 and $2.0 \mathrm{~g}$ used by Lodhi et al. (1994) and Thomas et al. (1993) protocols, respectively. Samples were performed in microcentrifuge tubes $(2 \mathrm{~mL})$ and the protocols were tested at least three times each using five different plants for experiments. The higher amount of DNA (ng/mg fresh weight) from $100 \mathrm{mg}$ leaves was obtained by the modified protocol of Thomas et al. (1993). DNA yields per sample ranged from 100 to $200 \mathrm{ng} / \mathrm{mg}$ using the Thomas et al. modified protocol and from 20 to $50 \mathrm{ng} / \mathrm{mg}$ using the Lodhi et al. modified protocol. According to Thomas et al., $100 \mathrm{mg}$ leaves from individual vines was ground to a fine powder in liquid nitrogen and homogenized in $1250 \mu \mathrm{L}$ buffer $\mathrm{A}(0.25 \mathrm{M} \mathrm{NaCl}, 0.2 \mathrm{M}$ Tris- $\mathrm{HCl}, \mathrm{pH} 8.0,50 \mathrm{mM}$ EDTA, $0.1 \mathrm{v} / \mathrm{v} 2-$ mercaptoethanol, $2.5 \% \mathrm{w} / \mathrm{v}$ polyvinyl-pyrolidone 40,000$)$. A crude nuclear pellet was obtained by centrifugation at $4000 \mathrm{~g}$ for $10 \mathrm{~min}$ at $4^{\circ} \mathrm{C}$. Pellet was resuspended in $700 \mu \mathrm{L}$ extraction buffer B $(0.5 \mathrm{M} \mathrm{NaCl}, 0.2 \mathrm{M}$ Tris-HCl, $\mathrm{pH} 8.0,50 \mathrm{mM}$ EDTA, 1\% v/v 2-mercaptoethanol, $2.5 \% \mathrm{w} / \mathrm{v}$ polyvinyl-pyrolidone, $3 \%$ sarcosyl, $20 \%$ ethanol) and incubated at $37^{\circ} \mathrm{C}$ for $45 \mathrm{~min}$. After incubation, an equal volume of chloroform/isoamyl alcohol (24:1) was added and the phases were separated by centrifugation at $16,000 \mathrm{~g}$ for $10 \mathrm{~min}$. The aqueous layer was collected and 0.54 volume of cold isopropanol $\left(-20^{\circ} \mathrm{C}\right)$ added to precipitate the DNA. The DNA pellet was obtained after centrifugation at $16,000 \mathrm{~g}$ for $10 \mathrm{~min}$ and resuspended in $100 \mu \mathrm{L}$ TE (10 mM Tri-HCl, pH 8.0, 1 mM EDTA) containing $15 \mu \mathrm{g} / \mathrm{mL}$ RNAse A and incubated for 30 min at $37^{\circ} \mathrm{C}$. Protein was removed by adding $50 \mu \mathrm{L} 7.5 \mathrm{M}$ ammonium acetate, followed by centrifugation at $16,000 \mathrm{~g}$ for $10 \mathrm{~min}$. DNA in the supernatant was precipitated with a 0.54 volume of cold isopropanol; the pellet was dried at room temperature resuspended in $100 \mu \mathrm{L}$ $\mathrm{TE}$ and stored at $4^{\circ} \mathrm{C}$. 


\begin{tabular}{|c|c|c|c|c|}
\hline Vine & Cultivar & $\begin{array}{l}\text { Berry } \\
\text { color }\end{array}$ & Region & $\begin{array}{c}\text { Date of } \\
\text { collection }\end{array}$ \\
\hline 1 & Italia & G & Marialva & $08 / 22,2003$ \\
\hline 2 & Italia & G & Marialva & $08 / 22,2003$ \\
\hline 3 & Italia & G & Marialva & $08 / 22,2003$ \\
\hline 4 & Italia & G & Marialva & $08 / 22,2003$ \\
\hline 5 & Italia & G & Marialva & $08 / 22,2003$ \\
\hline 6 & Italia & G & Marialva & $08 / 22,2003$ \\
\hline 7 & Italia & G & Marialva & $08 / 22,2003$ \\
\hline 8 & Italia & G & Paiçandu & $10 / 03,2003$ \\
\hline 9 & Italia & G & Paiçandu & $10 / 03,2003$ \\
\hline 10 & Italia & $\mathrm{G}$ & Paiçandu & $10 / 03,2003$ \\
\hline 11 & Italia & G & Paiçandu & $10 / 03,2003$ \\
\hline 12 & Italia & G & Paiçandu & $10 / 03,2003$ \\
\hline 13 & Italia & G & Paiçandu & $10 / 03,2003$ \\
\hline 14 & Italia & G & Paiçandu & $10 / 03,2003$ \\
\hline 15 & Brasil & B & Marialva & $08 / 22,2003$ \\
\hline 16 & Brasil & B & Marialva & $08 / 22,2003$ \\
\hline 17 & Brasil & B & Marialva & $08 / 22,2003$ \\
\hline 18 & Brasil & B & Marialva & $08 / 22,2003$ \\
\hline 19 & Brasil & B & Marialva & $08 / 22,2003$ \\
\hline 20 & Brasil & B & Marialva & $08 / 22,2003$ \\
\hline 21 & Brasil & B & Marialva & $08 / 22,2003$ \\
\hline 22 & Brasil & B & Paiçandu & $10 / 03,2003$ \\
\hline 23 & Brasil & B & Paiçandu & $10 / 03,2003$ \\
\hline 24 & Brasil & B & Paiçandu & $10 / 03,2003$ \\
\hline 25 & Brasil & B & Paiçandu & $10 / 03,2003$ \\
\hline 26 & Brasil & B & Paiçandu & $10 / 03,2003$ \\
\hline 27 & Brasil & B & Paiçandu & $10 / 03,2003$ \\
\hline 28 & Brasil & B & Paiçandu & $10 / 03,2003$ \\
\hline 29 & Benitaka & IRR & Marialva & $08 / 22,2003$ \\
\hline 30 & Benitaka & IRR & Marialva & $08 / 22,2003$ \\
\hline 31 & Benitaka & IRR & Marialva & $08 / 22,2003$ \\
\hline 32 & Benitaka & IRR & Marialva & $08 / 22,2003$ \\
\hline 33 & Benitaka & IRR & Marialva & $08 / 22,2003$ \\
\hline 34 & Benitaka & IRR & Marialva & $08 / 22,2003$ \\
\hline 35 & Benitaka & IRR & Marialva & $08 / 22,2003$ \\
\hline 36 & Benitaka & IRR & Paiçandu & $10 / 03,2003$ \\
\hline 37 & Benitaka & IRR & Paiçandu & $10 / 03,2003$ \\
\hline 38 & Benitaka & IRR & Paiçandu & $10 / 03,2003$ \\
\hline 39 & Benitaka & IRR & Paiçandu & $10 / 03,2003$ \\
\hline 40 & Benitaka & IRR & Paiçandu & $10 / 03,2003$ \\
\hline 41 & Benitaka & IRR & Paiçandu & $10 / 03,2003$ \\
\hline 42 & Benitaka & IRR & Paiçandu & $10 / 03,2003$ \\
\hline 43 & Rubi & LRR & Marialva & $08 / 22,2003$ \\
\hline 44 & Rubi & LRR & Marialva & $08 / 22,2003$ \\
\hline 45 & Rubi & LRR & Marialva & $08 / 22,2003$ \\
\hline 46 & Rubi & LRR & Marialva & $08 / 22,2003$ \\
\hline 47 & Rubi & LRR & Marialva & $08 / 22,2003$ \\
\hline 48 & Rubi & LRR & Marialva & $08 / 22,2003$ \\
\hline 49 & Rubi & LRR & Marialva & $08 / 22,2003$ \\
\hline 50 & Rubi & LRR & Paiçandu & $10 / 03,2003$ \\
\hline 51 & Rubi & LRR & Paiçandu & $10 / 03,2003$ \\
\hline 52 & Rubi & LRR & Paiçandu & $10 / 03,2003$ \\
\hline 53 & Rubi & LRR & Paiçandu & $10 / 03,2003$ \\
\hline 54 & Rubi & LRR & Paiçandu & $10 / 03,2003$ \\
\hline 55 & Rubi & LRR & Paiçandu & $10 / 03,2003$ \\
\hline
\end{tabular}

G: green; B: black; IRR: intense rosy-red; LRR: light rosy-red. 
After extraction, the quality of isolated DNA was determined by electrophoresis on a 0.8\% agar gel (Hoisington et al., 1994).

Amplification reactions, as a rule, were carried out according to Williams et al. (1990), with minor modifications. Amplification reactions were performed in an aseptic chamber using volumes of $20 \mu \mathrm{L}$ containing 50 or $70 \mathrm{ng}$ genomic DNA, $10 \mathrm{mM}$ Tris- $\mathrm{HCl}, \mathrm{pH} 8.8,2.0$ or 2.5 $\mathrm{mM} \mathrm{MgCl}, 50 \mathrm{mM} \mathrm{KCl}, 0.1 \%$ Triton X-100, 0.1 or $0.2 \mu \mathrm{M}$ each of dATP, dGTP, dCTP, dTTP, $0.5 \mu \mathrm{M}$ primer and 0.5 or 0.75 unit Taq polymerase (Operon-BRL). Ten-mer primers were used in the amplification reactions. Amplifications were performed, in duplicate, with a personal Eppendorf Mastercycler Gradient using three different programs. The polymerase chain reaction conditions tested were: Program 1) denaturation for $5 \mathrm{~min}$ at $94^{\circ} \mathrm{C}, 45$ cycles at $94^{\circ} \mathrm{C}$ for $1 \mathrm{~min}$, $35^{\circ} \mathrm{C}$ for $1 \mathrm{~min}$ and $72^{\circ} \mathrm{C}$ for $2 \mathrm{~min}$, with a final 7 -min extension at $72^{\circ} \mathrm{C}$; Program 2) denaturation for $5 \mathrm{~min}$ at $94^{\circ} \mathrm{C}, 45$ cycles at $94^{\circ} \mathrm{C}$ for $30 \mathrm{~s}, 35^{\circ} \mathrm{C}$ for $30 \mathrm{~s}$ and $72^{\circ} \mathrm{C}$ for $1 \mathrm{~min}$, with a final 5-min extension at $72^{\circ} \mathrm{C}$; Program 3) denaturation for $5 \mathrm{~min}$ at $94^{\circ} \mathrm{C}, 45$ cycles at $94^{\circ} \mathrm{C}$ for $45 \mathrm{~s}, 35^{\circ} \mathrm{C}$ for $45 \mathrm{~s}$ and $72^{\circ} \mathrm{C}$ for $1 \mathrm{~min}$, with a final 5 -min extension at $72^{\circ} \mathrm{C}$.

Amplification products were separated by electrophoresis on 1.5 and $2 \%$ agar TAE gels at $60 \mathrm{~V}$ for $6 \mathrm{~h}$. Gels were stained with ethidium bromide $(0.5 \mathrm{mg} / \mathrm{mL})$ and recorded by image capture in a High Performance Ultraviolet Transilluminator - Edas 290 using Kodak 1D 3.5 program. DNA ladder (1 kb; Gibco-BRL) was used as size marker.

After the establishment of amplification reactions using the OPA-13 and OPB-05 primers, a total of 70 primers of OPA, OPB, OPE, OPF, OPI, OPM, and OPP kits (Operon Technologies Inc., USA) were used in the amplification reaction. Fragments were analyzed by comparing the RAPD profiles of each plant in terms of presence or absence of each DNA fragment. Only intense bands that showed repeatable patterns were scored. Similarity between plants was calculated with Jaccard's coefficient, while UPGMA cluster analysis was performed with the NTSYS-pc software (Rohlf, 1989).

\section{RESULTS}

Reproducible banding patterns were obtained with amplification reactions in volumes of $20 \mu \mathrm{L}$ containing $50 \mathrm{ng}$ genomic DNA, $10 \mathrm{mM}$ Tris- $\mathrm{HCl}, \mathrm{pH} 8.8,2.5 \mathrm{mM} \mathrm{MgCl}, 50 \mathrm{mM} \mathrm{KCl}$, $0.1 \%$ Triton X-100, $0.2 \mu \mathrm{M}$ each of dATP, dGTP, dCTP, dTTP, $0.5 \mu \mathrm{M}$ primer and 0.75 unit Taq polymerase (Operon-BRL), and using Program 3 (denaturation for 5 min at $94^{\circ} \mathrm{C}, 45$ cycles at $94^{\circ} \mathrm{C}$ for $45 \mathrm{~s}, 35^{\circ} \mathrm{C}$ for $45 \mathrm{~s}$ and $72^{\circ} \mathrm{C}$ for $1 \mathrm{~min}$, with a final 5 -min extension at $72^{\circ} \mathrm{C}$ ).

Among the 70 primers, 13 (OPA-13, OPB-01, OPB-07, OPE-03, OPE-14, OPE-15, OPF-05, OPM-03, OPP-08, OPP-10, OPF-13, OPP-07, and OPB-05) produced amplified DNA segments after an initial primer screening using DNA of the two Italia cultivar plants, but only 10 primers were used for RAPD fingerprints. These primers yielded reproducible patterns for all scored bands in the analysis carried out and were applied to all 55 vine samples (14 cultivar Italia, 14 cultivar Brasil, 14 cultivar Benitaka, and 13 cultivar Rubi). For each primer, only one mix was prepared, which was used for simultaneous comparison of the 55 individual samples in the same amplification reaction. Figure 1 illustrates the RAPD markers observed using different primers (parts of the gels, from different amplification reactions used for simultaneous comparison of the 55 individual samples); in cultivar Italia using the OPE-15 (Figure 1A) and OPM-03 (Figure 1C) primers, in cultivar Benitaka using the OPP-08 primer (Figure 1B), and in cultivar Brasil using the OPE-14 primer (Figure 1D), where only the strongest staining DNA segments were scored. 

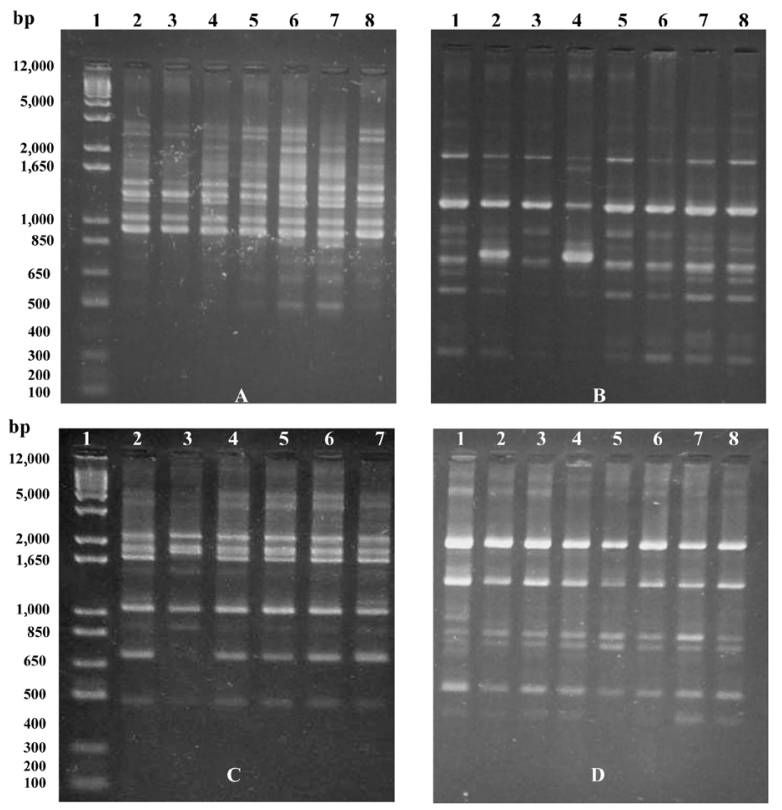

Figure 1. Random amplified polymorphic DNA fingerprinting from Italia, Rubi, Benitaka, and Brasil cultivars of Vitis vinifera obtained with primers OPE-15 (A: lanes 2-8, cultivar Italia), OPP-08 (B: lanes 1-7, cultivar Benitaka; lane 8, cultivar Rubi), OPM-03 (C: lanes 2-7, cultivar Italia), and OPE-14 (D: lanes 1-8, cultivar Brasil) from Operon Technologies Inc. (USA) on the samples of genomic DNA. The 1-kb ladder was used as molecular weight marker.

The 10 RAPD primers generated 126 reproducible and well-defined segments (Table 2) of which 63, 68, 76, and 72 were polymorphic in Italia, Rubi, Benitaka, and Brasil cultivars of $V$. vinifera, respectively. The total number of polymorphic segments for the four cultivars was 82 . The number of segments for each primer varied from 7 to 18 with an average of 12.6 segments per primer. The size of the amplified products ranged from 300 to $5000 \mathrm{bp}$. Primer OPP-08 generated the highest number of segments among the primers, whereas OPE-15 primer showed the greatest capacity for discriminating polymorphic segments in the four $V$. vinifera cultivars (Table 2).

Table 2. Polymorphic fragments in Italia, Rubi, Benitaka, and Brasil cultivars of Vitis vinifera.

\begin{tabular}{|c|c|c|c|c|c|c|}
\hline \multirow[t]{2}{*}{ Primer } & \multirow[t]{2}{*}{ NTF } & \multicolumn{5}{|c|}{ Number of polymorphic fragments } \\
\hline & & Italia & Rubi & Benitaka & Brasil & NTPF \\
\hline OPA-13 & 12 & 6 & 7 & 7 & 8 & 8 \\
\hline OPB-01 & 8 & 5 & 5 & 5 & 4 & 5 \\
\hline OPB-07 & 12 & 5 & 6 & 8 & 5 & 8 \\
\hline OPE-03 & 13 & 3 & 4 & 6 & 5 & 6 \\
\hline OPE-14 & 14 & 7 & 8 & 6 & 8 & 8 \\
\hline OPE-15 & 16 & 8 & 8 & 13 & 13 & 13 \\
\hline OPF-05 & 12 & 7 & 8 & 8 & 7 & 8 \\
\hline OPM- 03 & 14 & 7 & 8 & 5 & 6 & 8 \\
\hline OPP-08 & 18 & 10 & 9 & 13 & 11 & 13 \\
\hline OPP-10 & 7 & 5 & 5 & 5 & 5 & 5 \\
\hline Total & 126 & 63 & 68 & 76 & 72 & 82 \\
\hline
\end{tabular}

NTF: number of total fragments; NTPF: number of total polymorphic fragments. 
Actually, polymorphic banding patterns reflect the genomic variability $(65.1 \%)$ present in the four $V$. vinifera cultivars. Polymorphism among the four cultivars is large, since a high number of polymorphic bands were detected with only ten random 10-mer primers. Specific fragments, such as OPP-08-770 and OPP-08-1650, were detected only in cultivar Benitaka. Also, the OPP-10-1650 fragment was detected in the three colored cultivars, albeit absent in cultivar Italia.

The dendrogram generated with Jaccard's coefficient showed no grouping according to cultivars or locality (vineyards in Marialva and Paiçandu), where plants of Italia, Rubi, Benitaka, and Brasil cultivars were collected (Figure 2). The similarity coefficient within Italia cultivar ranged from 71.9 to $91.3 \%$, while it was from 65.8 to $89.5 \%, 61.4$ to $88.6 \%$, and 65.2 to $86.0 \%$ within Rubi, Benitaka and Brasil, respectively.

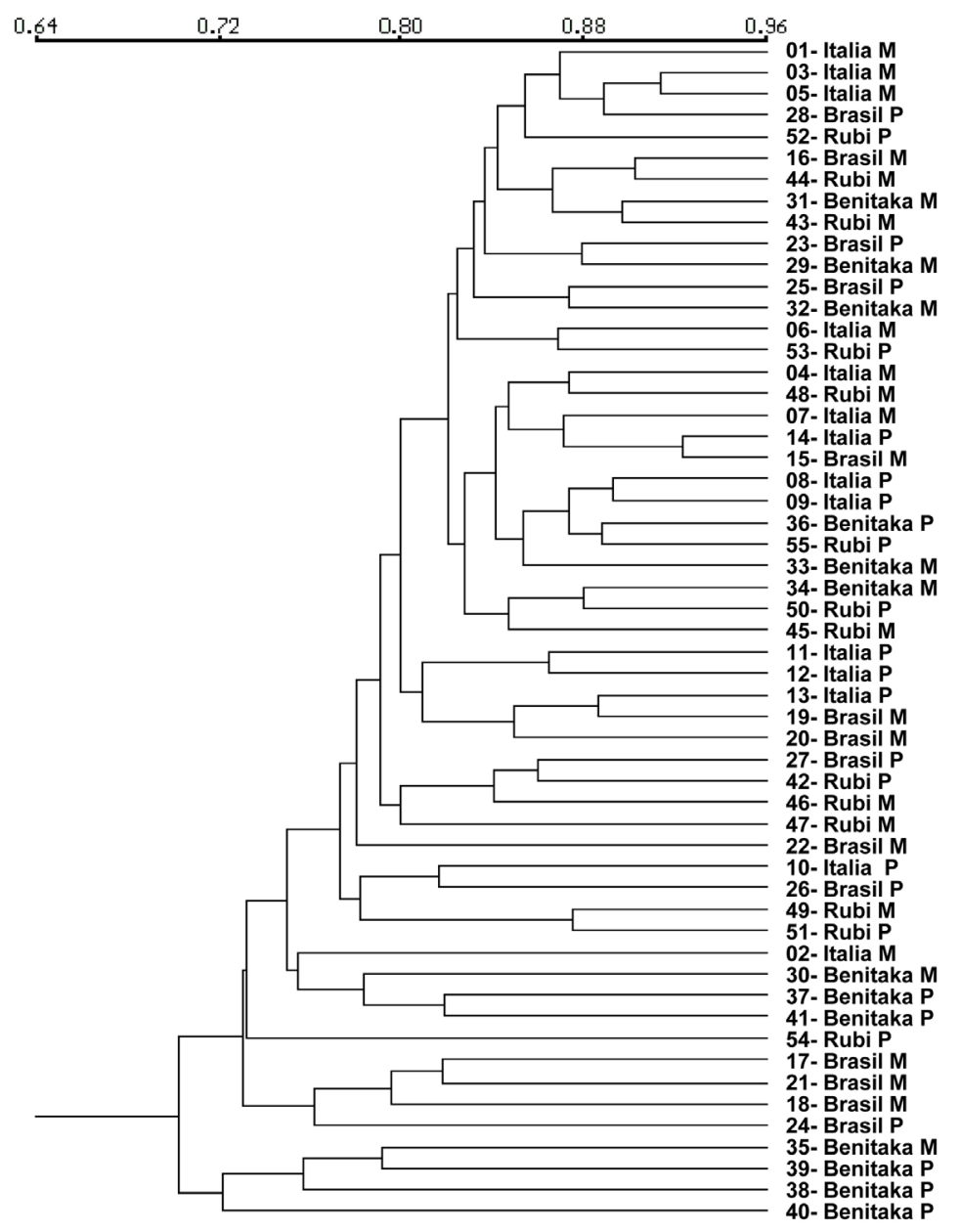

Figure 2. Dendrogram represents the relationship between the Italia, Rubi, Benitaka, and Brasil cultivars of Vitis vinifera from Marialva (M) and Paiçandu (P) regions in the State of Paraná, based on UPGMA cluster analysis of the random amplified polymorphic DNA profiles derived from 10 primers using Jaccard's similarity coefficient. 


\section{DISCUSSION}

The level of polymorphism found in our study (65.1\%) corroborated the high frequency of the null Est-3 carboxylesterase phenotypes (61.7\%) in the four $V$. vinifera clones (Orasmo et al., 2007) and also previous RAPD studies using different cultivars or varieties of grapes (Fanizza et al., 1999; Regner et al., 2000; Tamhankar et al., 2001; Luo and $\mathrm{He}, 2001)$. DNA polymorphism in clones of the other $4 \mathrm{~V}$. vinifera varieties has been detected using Southern hybridization (restriction fragment length polymorphism) and amplification (RAPD and inter-simple sequence repeat (SSR) sequences) techniques (Barysheva et al., 2003). This finding is in contrast with previously published monomorphic Pinot cultivars and clones (Tschammer and Zyprian, 1994; Ye et al., 1998).

We have noted that the frequency of polymorphic segments is higher within the color cultivars Rubi, Benitaka and Brasil than within cultivar Italia. High levels of polymorphism found in Italia, Rubi, Benitaka, and Brasil cultivars of $V$. vinifera are in accordance with the origin of these cultivars. Italia cultivar is a cross between Bicane and Muscat Hamburg and variations among the cultivars of the Muscat family have shown genetic similarity rates ranging from 0.66 to 1.00 (Stavrakakis and Biniari, 1998). The genetic variation in cultivar Italia (hybrid between Bicane x Muscat Hamburg) may be maintained as a result of clonal multiplications of Italia cultivar as well as of the Rubi, Benitaka, and Brasil cultivars. In grapevines, somatic cell mutations take place and are eventually fixed and transmitted to new individuals through vegetative propagation (Crespan, 2004). This high degree of polymorphism expressed by Italia, Rubi, Benitaka, and Brasil cultivars is highly important in stimulating breeding programs with other $V$. vinifera cultivars.

Intravarietal genetic diversification associated with geographical dispersal of $V$. vinifera cultivars (Cabernet Sauvignon cultivar) was detected by Moncada et al. (2006). However, in the present study, the dendrogram generated using Jaccard's coefficient showed no grouping according to cultivars or locality (vineyards in Marialva and Paiçan$\mathrm{du}$ ), where plants of Italia, Rubi, Benitaka, and Brasil cultivars were collected. Since the distribution of plants on cluster analysis indicated that no RAPD markers are associated with colored grapes and original clone (Italia cultivar), the hypothesis that non-colored and colored mutants constitute the same cultivar (Oliveira-Collet et al., 2005) is thus corroborated by the present data. Italia, Rubi, Benitaka, and Brasil cultivars could not be clearly differentiated genetically as individual cultivars using RAPD markers, suggesting therefore, that Rubi, Benitaka and Brasil represent different types or clones of the Italia cultivar.

The result of the present study has important economic implications since these cultivars have different commercial demands. The colored cultivars have shown higher commercial demands. Producers in the Marialva region believe that the colored clones are a genetically uniform material, but surprisingly they have observed that the Benitaka and Rubi vines exhibit several sectors with the green berry skin that is characteristic of the Italia cultivars. This phenotypic reversion occurred either on a side branch or on the same bunch of the cluster (Oliveira-Collet et al., 2005). Likewise, there are sectors in Brasil cultivar, which exhibited the red color of the berry skin, so characteristic of Benitaka cultivars. The change in frequency for berry skin color was explained by the occurrence of somatic crossing-over events or by insert-sequence elements interrupting the coding 
sequence of genes responsible for skin color in the colored (Rubi, Benitaka, and Brasil) grape cultivars (Oliveira-Collet et al., 2005). Differences in regulation of gene transcription, involving an enzyme catalyzing steps of the anthocyanin biosynthetic pathways and two mutations in the $V v M Y B A 2$ gene, have been reported as events responsible for the different berry colors (Kobayashi et al., 2001, 2004; Walker et al., 2007). Kobayashi et al. (2004) showed that the difference between red and white grape varieties is the presence of a retrotransposon in the promoter of the white version of the $V v M Y B A 1$ gene, leading to transcriptional inactivation of this gene. The retrotransposons occurring in white cultivars may explain the genetic variability at the DNA level in the Italia cultivar and likewise explain the genetic instability and diversity in Rubi, Benitaka, and Brasil clones. The transposition events in different sites of DNA (in coding and non-coding DNA segments) in cultivar Italia and their colored clones (retrotransposon-induced mutations) may determine the high polymorphism of random amplified DNA segments.

The genetic diversity revealed in the present study is contrary to a previous hypothesis that clones of Italia, Rubi, Benitaka, and Brasil are genetically uniform and confirmed our suspicion of genetic variation among the clones and within each clone. High temperatures have been indicated as a factor in the inhibition of anthocyanin accumulation in the skin of grape berries (Mori et al., 2007), but we believe that the accumulated mutations, occurring over 42 years of cultivation, may be responsible for genetic (RAPD) and morphological (berry skin color polymorphism) instability of the Rubi, Benitaka and Brasil cultivars. In addition, the periclinal chimerism phenomenon in long-lived clonally propagated crops, such as grapevine, also may have a role in clonal differences. A periclinal chimerism phenomenon determining clonal differences in grapevine (Pinot cultivar) has been reported by Franks et al. (2002) and Hocquigny et al. (2004) using SSR markers. A mutation in microsatellite allele-length was found within strains of each of the other four different varieties of $V$. vinifera (Crespan, 2004). SSR markers (Tautz, 1989) should be used to study the DNA polymorphism in Italia cultivar from different regions of Brazil and to determine the existing relationship among the four grape cultivars, which are traditionally grown in the rural region of Marialva (northwestern region of the State of Paraná, southern Brazil, where the Rubi, Benitaka, and Brasil cultivars arose).

In the present study, we showed how RAPD analysis can help us understand more about the table-grape cultivars Italia, Rubi, Benitaka, and Brasil, and their historical development, genetic diversity, and potential for genetic improvement. Our results show that RAPD markers are effective tools in detecting polymorphism in Italia, Rubi, Benitaka, and Brasil clones. Although many studies question the use of RAPD in examining genetic variability, improvements in the RAPD technique i) to obtain a higher amount of DNA, ii) to identify reproducible and well-separated DNA segments, and iii) to identify strongly stained DNA segments using different amplification programs, lead us to conclude that RAPD molecular markers are efficient. In fact, the RAPD technique demands little cost and time. The primers OPP-08 and OPE-15, for example, were indicated for generating the highest number of fragments and greatest potential for discriminating polymorphic fragments, respectively, in future molecular genetic analysis of $V$. vinifera clones. In practical terms, RAPD markers cannot be used for the discrimination of colored and non-colored clones of cultivar Italia but the Thomas et al. (2003) modified protocol and the primers selected in our study constitute a relatively simple procedure using im- 
portant markers to analyze the development of genetic diversity within each of the Italia, Rubi, Benitaka, and Brasil clones.

\title{
ACKNOWLEDGMENTS
}

\author{
Research supported by CNPq, CAPES, and Fundação Araucária - Foundation of the \\ State of Paraná, Brazil.
}

\section{REFERENCES}

Barysheva IA, Tulaeva MI and Chisnikov VS (2003). Study of the intra-cultivar variability of grape DNA using RFLP and PCR methods. Tsitol. Genet. 37: 31-38.

Camargo UA (1994). Uvas do Brasil. Empresa Brasileira de Pesquisa Agropecuária, Centro Nacional de Pesquisa de Uva e Vinho, Brasília.

Crespan M (2004). Evidence on the evolution of polymorphism of microsatellite markers in varieties of Vitis vinifera L. Theor. Appl. Genet. 108: 231-237.

Fanizza G, Colonna G, Resta P and Ferrara G (1999). The effect of the number of RAPD markers on the evaluation of genotypic distances in Vitis vinifera. Euphitica 107: 45-50.

Franks T, Botta R, Thomas MR and Franks J (2002). Chimerism in grapevines: implications for cultivar identity, ancestry and genetic improvement. Theor. Appl. Genet. 104: 192-199.

Hocquigny S, Pelsy F, Dumas V, Kindt S, et al. (2004). Diversification within grapevine cultivars goes through chimeric states. Genome 47: 579-589.

Hoisington D, Khairallah M and González-de-León D (1994). Laboratory Protocols: CIMMYT Applied Molecular Genetics Laboratory. 2nd edn. CIMMYT, Mexico.

Kishino AY and Mashima M (1980). Uva Vitis vinifera L. Fundação Instituto Agronômico do Paraná, Manual Agropecuário do Paraná, Londrina, 138-177.

Kobayashi S, Ishimaru M, Ding CK, Yakushiji H, et al. (2001). Comparison of UDP-glucose:flavonoid 3-O-glucosyltransferase (UFGT) gene sequences between white grapes (Vitis vinifera) and their sports with red skin. Plant Sci. 160: 543-550.

Kobayashi S, Goto-Yamamoto N and Hirochika H (2004). Retrotransposon-induced mutations in grape skin color. Science 304: 982.

Lodhi MA, Ye GN, Weeden NF and Reisch BI (1994). A simple and efficient method for DNA extraction from grapevine cultivars and Vitis species. Plant Mol. Biol. Rep. 12: 6-13.

Luo S and He P (2001). Discrimination of wild grapes native to China by RAPD markers. Vitis 40: 163-168.

Moncada X, Pelsy F, Merdinoglu D and Hinrichsen P (2006). Genetic diversity and geographical dispersal in grapevine clones revealed by microsatellite markers. Genome 49: 1459-1472.

Mori K, Goto-Yamamoto N, Kitayama M and Hashizume K (2007). Loss of anthocyanins in red-wine grape under high temperature. J. Exp. Bot. 58: 1935-1945.

Oliveira-Collet SA, Collet MA and Machado MFPS (2005). Differential gene expression for isozymes in somatic mutants of Vitis vinifera L. (Vitaceae). Biochem. Syst. Ecol. 33: 691-703.

Orasmo GR, Oliveira-Collet SA, Lapenta AS and de Fatima PSM (2007). Biochemical and genetic polymorphisms for carboxylesterase and acetylesterase in grape clones of Vitis vinifera L. (Vitaceae) cultivars. Biochem. Genet. 45: 663-670.

Regner F, Stadlbauer A, Eisenheld C and Kaserer H (2000). Genetic relationship among pinots and related cultivars. Am. J. Enol. Vit. 51: 7-14.

Rohlf FJ (1989). NTSYS-pc Numerical taxonomy and multivariate analysis system. Version 1.50. New York Exeter Publ., New York

Sousa JSI (1996). Uvas para o Brasil. Revista Anual de Piracicaba. 2nd edn. FEALQ, Piracicaba.

Stavrakakis MN and Biniari K (1998). Genetic study of grape cultivars belonging to the Muscat family by random amplified polymorphic DNA markers. Vitis 37: 119-122.

Tamhankar SA, Patil SG and Rao VS (2001). Assessment of the genetic diversity of some important grape genotypes in India using RAPD markers. Vitis 40: 157-161.

Tautz D (1989). Hypervariability of simple sequences as a general source for polymorphic DNA marker. Nucleic. Acids Res. 17: 6463-6471. 
Thomas MR, Matsumoto S, Cain P and Scott NS (1993). Repetitive DNA of grapevine: classes present and sequences suitable for cultivar identification. Theor. Appl. Genet. 86: 173-180.

Tschammer J and Zyprian E (1994). Molecular characterization of grapevine cultivars of Riesling-type and of closely related Burgundies. Vitis 33: 249-250.

Ulanovsky S, Gogorcena Y, Martínez de Toda F and Ortiz JM (2002). Use of molecular markers in detection of synonymies and homonymies in grapevines (Vitis vinifera L.). Sci. Hort. 92: 241-254.

Walker AR, Lee E, Bogs J, McDavid DA, et al. (2007). White grapes arose through the mutation of two similar and adjacent regulatory genes. Plant J. 49: 772-785.

Williams JG, Kubelik AR, Livak KJ, Rafalski JA, et al. (1990). DNA polymorphisms amplified by arbitrary primers are useful as genetic markers. Nucleic Acids Res. 18: 6531-6535.

Ye GNG, Soylemezoglu G, Weeden NF, Lamboy WF, et al. (1998). Analysis of the relationship between grapevine cultivars, sports and clones via DNA fingerprinting. Vitis 37: 33-38.

Zoghlami N, Mliki A and Ghorbel A (2001). Evaluation of genetic diversity among Tunisian grapevines by RAPD markers. Vitis 40: 31-37. 